\title{
Ontogenesis of Tet family of methylcytosine dioxygenase enzyme genes during Japanese rice fish (Oryzias latipes) embryogenesis: Effects of ethanol and 5-azacytidine
}

\author{
Asok K. Dasmahapatra ${ }^{\mathrm{a}, \mathrm{b}, *}$ and Ikhlas A. Khan ${ }^{\mathrm{a}, \mathrm{c}}$ \\ ${ }^{a}$ National Center for Natural Product Research, School of Pharmacy; ${ }^{b}$ Department of BioMolecular Sciences, \\ Pharmacology Division; ' Department of BioMolecular Sciences, Pharmacognosy Division, \\ University of Mississippi, University, MS 38677, USA.
}

\begin{abstract}
The mRNA expression pattern of tet family of methyl cytosine dioxygenase enzymes (ten-eleven translocation, tet 1 , tet 2 , and tet3), which catalyze the conversion of 5 -methylcytosine $(5 \mathrm{mC})$ to 5 hydroxymethylcytosine $(5 \mathrm{hmC})$ and initiate $5 \mathrm{mC}$ remodeling through active demethylation, was investigated in brain, ovary, and liver of Japanese rice fish (Oryzias latipes) adults, and in whole embryos after fertilization to hatching. Moreover, fertilized eggs were exposed to ethanol or 5azacytidine (5-azaC), 0-2 day post fertilization (dpf), and tet mRNAs on 2 and $6 \mathrm{dpf}$ were analyzed. Our data indicated that all three tet mRNAs were expressed in brain, liver, and ovary of adult fish with substantial variations. In embryos, all three tet mRNAs showed rhythmic expression, high copies in 1-3 dpf followed by down regulation until hatching. Embryonic exposure either to ethanol or 5 -azaC was unable to alter the expression of any of these tet mRNAs in $2 \mathrm{dpf}$; in $6 \mathrm{dpf}$, there was an increase in tet expression in response to high levels of ethanol (400-500 $\mathrm{mM})$ and 5-azaC (2 mM). Although we have previously documented that both ethanol and 5-azaC was able to induce fetal alcohol spectrum disorder (FASD)-like phenotypic features in Japanese rice fish, the present study indicates that the DNA demethylation by tet may differ between these two compounds.
\end{abstract}

\footnotetext{
*Corresponding author: asok@olemiss.edu
}

KEYWORDS: RT-qPCR, epigenetics, Tet, ethanol, 5-azacytidine, Japanese rice fish

\section{INTRODUCTION}

In vertebrates, methylation of DNA at the fifth position of cytosine residues (5-methylcytosine, $5 \mathrm{mC}$ ) in $\mathrm{CpG}$ dinucleotides is associated with gene silencing which is essential for normal development [1]. The "fifth base" $(5 \mathrm{mC})$, is maintained by DNA methyl transferase 1 (DNMT1) during DNA replication $[2,3]$. However, for activation of genes during fertilization and early stages of embryonic development, remodeling of $5 \mathrm{mC}$ (demethylation) is necessary [4-7]. Until now, two types of DNA demethylation processes, active and passive, have been established [8]. In passive demethylation, rapid proliferation by DNA replication occurs in cells and due to downregulation of DNMT1 enzyme $5 \mathrm{mC}$ is diluted [9]. In active demethylation, $5 \mathrm{mC}$ is enzymatically processed and removed by the teneleven translocation proteins (Tet1, Tet2, and Tet3) that convert $5 \mathrm{mC}$ to 5-hydroxymethylcytosine $(5 \mathrm{hmC})$ and also to its oxidative derivatives 5formylcytosine (5fC) and 5-carboxylcytosine $(5 \mathrm{caC})$ $[10,11]$. Mammalian embryos, after fertilization, employ a combination of both active and passive mechanisms of DNA remodeling; however, in zebrafish passive mechanism of $5 \mathrm{mC}$ dilution is predominant $[12,13]$. It was suggested that the conversion of $5 \mathrm{mC}$ to $5 \mathrm{hmC}$ and its derivatives by the TET enzymes is the initial step of DNA base- 
excision repair pathway which leads to transcriptional reactivation of the silenced genes.

Despite the role played by TET proteins during embryogenesis, initially these proteins were described as fusion partners of the myeloid/lymphoid or mixed lineage leukemia (MLL) gene in acute myeloid leukemia [14, 15]. Studies on Tet genes have revealed their expression patterns in various cell types and tissues which are very different [16-20]. TET1 is extremely important for maintaining embryonic stem cell pluripotency and inner cell mass specification $[16,21]$. Disruption of TET2 could impair hematopoietic cell homeostasis [22-24]. TET3 is involved in the epigenetic reprogramming of zygotic paternal DNA after fertilization [18]. Homozygous mutation of Tet 1 , Tet 2 or Tet 3 is compatible with mouse embryonic development; however, Tet3 mutant mice die perinatally [25]. Moreover, Tet1 and Tet2-defficient mice can survive, but Tet2 deficiency can lead to myeloid malignancies [21, 26, 27]. Combined knockdown of both Tet1 and Tet 2 genes did not affect survivability; however, perinatal lethality was observed [21]. Deletion of Tet3 leads to neonatal lethality [18]. All the Tet enzymes (Tet1, Tet2, and Tet3) and $5 \mathrm{hmC}$ are abundantly expressed in the brain of mammalian adults [28-32]. The 5-hmC level in the liver of patients suffering from nonalcoholic fatty liver disease was not significantly different from the normal (control) subjects [33]. Moreover, TET enzymes (TET1, 2, and 3) are also expressed in human testis and their expression is important in male fertility [34]. Tet3 overexpression played significant role in mouse oocytes during natural and accelerated aging [35]. Therefore Tet enzymes play a significant role in development as well as other body functions in adults.

While studying the importance of epigenetic mechanisms associated with the induction of fetal alcohol spectrum disorder (FASD) phenotypes during Japanese rice fish (Oryzias latipes) embryogenesis (which is also known as Japanese medaka fish), we have observed that dnmt mRNAs (dnmt1, dnmt3aa, dnmt3ba, and dnmt3bb.1) were expressed in this fish and both ethanol and 5-azacytidine (5-azaC) were able to modulate the expression pattern of these enzymes at the transcription level [36, 37]. All the studied dnmts in Japanese rice fish followed a unique expression pattern which could be used as an index of genomic DNA methylation during development [36, 37]. Available reports on DNA methylation studies in Japanese rice fish embryogenesis documented that vast majority of genomic DNA ( $>90 \%)$ is methylated at CCGG sites and methylation in these sites (CCGG) remained almost unchanged during the entire period of embryogenesis (from 16-cell stage to hatching) [38]. Our data on dnmt mRNA expression during Japanese rice fish development $[36,37]$ were partially supportive to this study because all the dnmt mRNAs are at the peak level of expression during early phases of embryogenesis (1-2 day post fertilization; Iwamatsu developmental stages 17 to 28 which is equivalent to neurula to 30 somite stage). Reduced expression of all these $d n m t$ mRNAs in later stages of development (from 3 day post fertilization to hatching; Iwamatsu stages 29 to 40 , or 34 somite stage to hatching), was probably due to downregulation of these enzymes (dnmts) that could induce activation of other silenced genes which should be turned on as development advances [39]. We hypothesized that even though the genomic DNAs were highly methylated during the entire period of embryogenesis at CCGG sites in Japanese rice fish [38], demethylation processes might be operative in this species that lead to the activation of the expression of required genes which are necessary for normal development. In the current investigation, we focus on the active mechanisms of DNA demethylation giving emphasis to the ontogenesis of tet mRNAs (tet1, tet2, and tet3) during Japanese rice fish embryogenesis (from zero dpf until hatching). Moreover, to identify any role played by ethanol in modulating active DNA demethylation processes while inducing FASD phenotypes in this species [40], we investigated the tet mRNA expression in FASD phenotypes and compared the effects with the embryos exposed to 5 -azaC (the potent inhibitor of DNMT) during development. Our data showed that although in adult fish, the brain expressed substantially high levels of tet mRNAs compared to ovary and liver, in embryos, tet mRNAs, like dnmts, maintained a developmental rhythm, expressed high copies during early phases of development ( 1 to $3 \mathrm{dpf}$ ) followed by down regulation (from 4 dpf until hatching); both ethanol (higher concentrations) and 5-azaC were able to modulate the expression pattern of these mRNAs at the transcription level which was observed only in the later stage ( $6 \mathrm{dpf})$ of development. 


\section{MATERIALS AND METHODS}

The Institutional Animal Care and Use Committee (IACUC) of the University of Mississippi (UM) approved all the experimental protocols.

\section{Animal rearing, embryo collection, and exposure to ethanol and 5-azaC}

Methods of animal maintenance, collection of fertilized eggs, identification of the different developmental stages [41] and the culture conditions of Japanese rice fish embryos in our laboratory have been described previously [36, 42]. In brief, the orange-red varieties of adult Japanese rice fish (breeders) were maintained in balanced salt solution (BSS, $17 \mathrm{mM} \mathrm{NaCl}, 0.4 \mathrm{mM} \mathrm{KCl}, 0.3 \mathrm{mM}$ $\mathrm{MgSO}_{4}$, and $0.3 \mathrm{mM} \mathrm{CaCl}, \mathrm{pH}$ 7.4) in Aquatic Habitats ZF0601 Zebrafish Stand-Alone system (Aquatic Habitats, Apoka, FL). The fish were fed twice daily with TetraMin flakes and brine shrimp nauplii (Artemia). Fertilized eggs after collection and screening were maintained in embryo-rearing medium (ERM) $(17 \mathrm{mM} \mathrm{NaCl}, 0.4 \mathrm{mM} \mathrm{KCl}, 0.6 \mathrm{mM}$ $\mathrm{MgSO}_{4}, 0.36 \mathrm{mM} \mathrm{CaCl}$, pH 7.4 with $0.0002 \%$ methylene blue to reduce fungal infection) under a 16L:8D light cycle in a Precision High Performance Incubator (Thermo Fisher Scientific, Waltham, MA, USA) at $26 \pm 1{ }^{\circ} \mathrm{C}$. For studies on tet1, tet2, and tet 3 mRNA expression during embryogenesis, the collected zero dpf embryos were maintained in clear glass bowls $(10 \times 4.5 \mathrm{~cm})$ in $150-200 \mathrm{~mL}$ ERM (50-100 embryos/bowl) with 50\% static renewal of the media every day. Viable zero(Iwamatsu stage 9-10), 1- (Iwamatsu stage 17-18), 2- (Iwamatsu stage 23-25), 3- (Iwamatsu stage 2728), 4- (Iwamatsu stage 29-30), and 6-dpf (Iwamatsu stage 34-38) embryos and hatchlings (within 24h of hatching) were used for RNA extraction (6-8 embryos or hatchlings of respective days of development were pooled per sample). To observe the organ-specific expression of tet genes, four reproductively active adult males and four egglaying female fish were used for collection of brain (male and female), liver (female) and ovarian (female) tissues. To study the effects of ethanol (100-500 $\mathrm{mM})$ and 5-azaC (2 mM) on tet1, tet2 and tet3 mRNA expression at the transcription level, viable zero-dpf embryos (Iwamatsu stage 9-10) were transferred to $2 \mathrm{~mL}$ tubes (1 egg/tube) in $1 \mathrm{~mL}$ medium (ERM) containing either 100-500 $\mathrm{mM}$ of ethanol or $2 \mathrm{mM}$ of 5-azaC (5-azacytidine, SigmaAldrich, St. Louis, MO) depending upon the nature of the experiment. The tubes were tightly capped to stop evaporative loss of the medium. Control embryos were maintained in $1 \mathrm{~mL}$ ERM (1 egg/tube) in identical conditions. The medium was changed every day. Some of the control and ethanol (100$500 \mathrm{mM})$ and 5-azaC (2 $\mathrm{mM})$-treated embryos after 2 days of treatment were utilized for RNA extraction or were transferred to a 48-well plate and maintained in ERM (one embryo/well $/ \mathrm{mL}$ medium, no ethanol or 5-azaC) for another 4 days (2-6 dpf) with $50 \%$ static renewal of the media and on $6 \mathrm{dpf}$ the viable embryos were used for RNA extraction.

\section{RNA isolation, cDNA synthesis, priming strategy, and Real-Time quantitative polymerase chain reaction (RT-qPCR)}

After the required period, the viable embryos were pooled (6-8 per sample) and homogenized in TRIzol reagent (Invitrogen, Carlsbad, CA) for RNA extraction following the manufacturer's instruction. The brain of adult male and female fish and the liver and ovary of egg laying female fish were also used for RNA extraction. To remove genomic DNA from the samples, the extracted RNA was treated with RNase-free RQ1 DNase (Promega, Madison, WI). The concentration of the purified RNA was determined in a Nano Drop (Thermo Scientific, Wilmington, DE) and the quality of the purified RNA was evaluated by $1 \%$ agarose gel electrophoresis. All purified RNA showed two distinct $18 \mathrm{~S}$ and $28 \mathrm{~S}$ ribosomal RNA bands in 1\% agarose gel electrophoresis and the 260:280 nm ratios determined in Nano drop (Thermo Fisher Scientific, Waltham, MA) were within 1.8-2.0. Purified RNA (200 ng$1 \mu \mathrm{g}$ ) was reverse transcribed to cDNA by iScript supermix (BioRad Laboratories, Hercules, CA), in a $20 \mu \mathrm{l}$ final volume following the manufacturer's protocol (iScript supermix uses a combination of oligo-dT and random hexamers for priming cDNA synthesis. Gene-specific primers (IDT, Coralville, IA) were designed from the sequences reported in the GenBank (Table 1), and annealing temperatures $\left(50-70{ }^{\circ} \mathrm{C}\right)$ were optimized by gradient PCR (annealing temperatures ranged from $50-70{ }^{\circ} \mathrm{C}$ for $1 \mathrm{~min}$ ). For confirmation of the amplification of right gene product the gel-purified PCR products (tet1, tet2, tet3) were ligated to pGEMT Easy vector, 
Table 1. List of primers used for amplification of tet methylcytosine dioxygenase (tet) genes in Japanese rice fish.

\begin{tabular}{|c|c|c|c|c|c|}
\hline $\begin{array}{c}\text { Name of } \\
\text { the gene }\end{array}$ & Sense (5'-3') & Antisense (5'-3') & $\begin{array}{c}\text { Annealing } \\
\left.\text { temperature } \mathbf{(}^{\circ} \mathbf{C}\right)\end{array}$ & $\begin{array}{c}\text { Product } \\
\text { size }\end{array}$ & Gene ID \\
\hline tet1 & ggtcgtccttttctggagtc & ccaaactcatccgtatcagagacc & 63 & 197 & XM_011493199.1 \\
\hline tet2 & catgtgcatgccagggattaaacc & gctctgtgctcatgttccacc & 60 & 256 & XM_004065914.2 \\
\hline tet3 & ccgattgctaagtgggtgatc & gaggccgcagcgtcggctggtg & 63 & 216 & XM_011479542.1 \\
\hline
\end{tabular}

and transformed into the JM109 strain of E. coli (Promega, Madison, WI) and the plasmid DNA was prepared by miniprep. The nucleotide sequences of the plasmid DNAs were determined by Retrogen (San Diego, CA). All the amplicons showed 100\% sequence identity with the sequences reported in the GenBank. The quantitative standards used in the RT-qPCR analysis for each target gene (tet1, tet2, and tet3) were prepared by PCR, using cDNA templates either from normal hatchling or zero dpf embryos (Iwamatsu stages 9-10) amplified with the same sets of sense and antisense primers (Table 1). The amplified standards were shown as single band in $1 \%$ agarose gel at the right base pair position (compared with 100 bp DNA ladder; New England Biolabs, Ipswich, MA) and were purified and quantified by Nanodrop 2000c (Thermo Fisher Scientific, Waltham, MA). The standards once prepared were aliquoted out into separate tubes and stored at $-80{ }^{\circ} \mathrm{C}$ until use. During RTqPCR analysis [43], the respective standard was serially diluted with nuclease-free water to the desired concentrations $\left(\sim 10^{1}-10^{7}\right.$ copy number $\left./ \mu \mathrm{L}\right)$ and run parallel with the samples. For each target gene $1 \mu \mathrm{L}$ of cDNA or standards in duplicate in a total reaction volume of $20 \mu \mathrm{L}(10 \mu \mathrm{L} 2 \mathrm{x}$ SYBR Green qPCR Master Mix from Biotool.com, $50 \mathrm{pM}$ each of forward and reverse primers of the target gene, $1 \mu \mathrm{L}$ cDNA or standards, and the volume was adjusted to $20 \mu \mathrm{L}$ by nuclease-free water) was amplified in a thermal cycler (CFX Connect Real Time System, BioRad). Standards were run each time in every set of RT-qPCR analysis. The copy numbers of RNA in each tube were determined by using a software program (CFX manager software, Bio-Rad laboratories, Hercules, CA). The data were expressed as copy number of target gene mRNA/ng of total RNA [43].

\section{Statistics}

The experiments were repeated at least 3 times and the data (Figures 1-4 and Table 2) were analyzed by using one way analysis of variance (ANOVA) followed by post-hoc Tukey's multiple comparison test. Data were expressed as mean \pm SEM of 4-10 observations and $p<0.05$ was considered as significant.

\section{RESULTS}

Expression of tet1, tet2, and tet 3 were found to be organ- specific in Japanese rice fish adults

By applying RT-qPCR technique and using genespecific primers (Table 1), we have analyzed the expression of tet 1 , tet2, and tet3 mRNAs (mRNA copy/ng RNA) in the brain of both male and female fish (reproductively active) and in the liver, and ovary of egg-laying female fish (Table 2). Our data indicated that all three tet mRNAs were expressed in these organs in adult stages. Among these three organs (brain, liver, and ovary) all three tet mRNA transcripts were found to be at the highest level of expression in brain even though the expression of tet 1,2 and 3 mRNAs in male and female brain was found to be identical (not significantly different). Compared to other two organs (brain and ovary) the liver showed the lowest level of expression $(p<0.05)$ (Table 2). Further comparison of the data showed that among these three tet genes, the mRNA transcripts (copies) of tet1 was found to be at the highest level in all of these organs and tet2 to be the lowest (Table 2); however, the values were not significantly different $(p<0.05)$.

\section{Developmental regulation of tet1, tet2, and tet3 mRNAs during Japanese rice fish embryogenesis}

The mRNA expression patterns of tet1, tet2, and tet3 during Japanese rice fish embryogenesis were investigated starting from zero dpf (Iwamatsu stage 9-10; early blastula) to hatching (Iwamatsu stage 40) by RT-qPCR using gene-specific primers (Table 1). During development, the expression pattern of tet1, 2 and 3 mRNAs maintained three distinct 

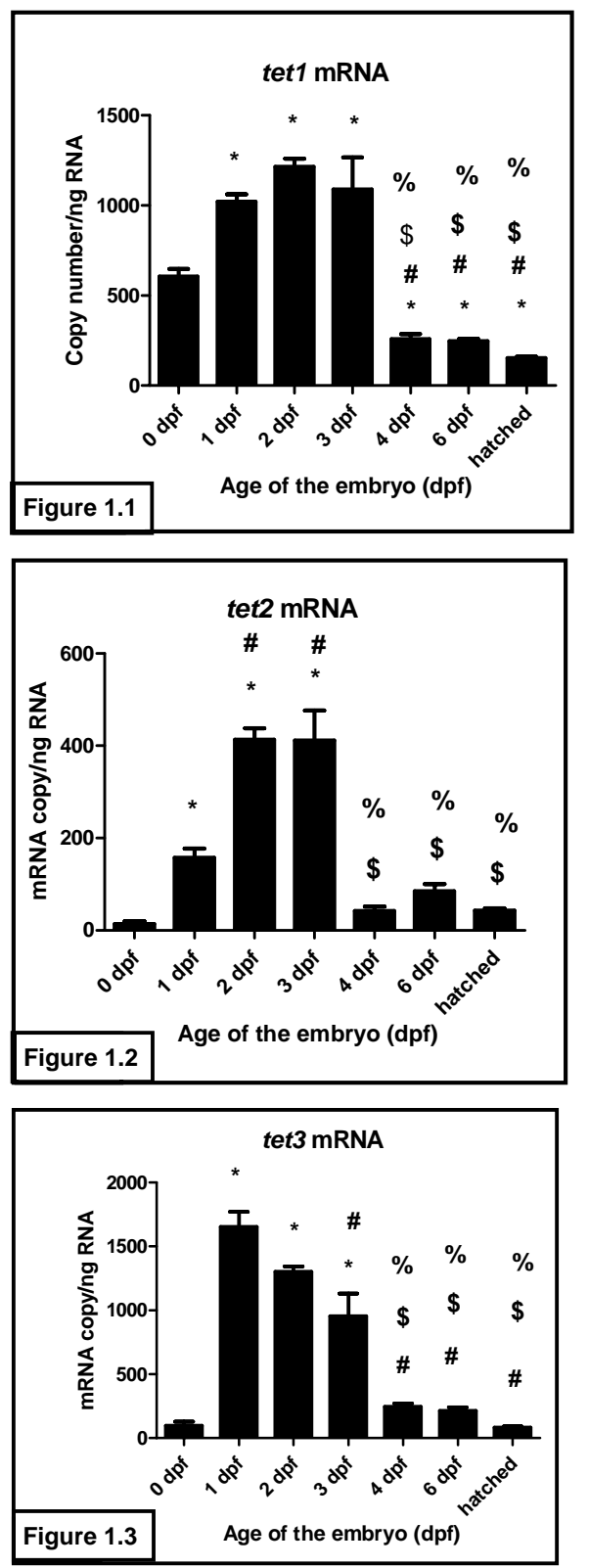

Figure 1. Expression of tet1, tet 2 and tet3 mRNAs during Japanese rice fish embryogenesis. Total RNA was prepared from 6 to 8 pooled Japanese rice fish embryos or hatchlings, reverse transcribed and analyzed by RTqPCR. The data were analyzed by one-way ANOVA followed by post-hoc Tukey's multiple comparison test; $p<0.05$ was considered as significant. Each bar is the mean \pm SEM of four to ten observations. Bar heads with asterisks (*), pound (\#), dollar (\$), and percent (\%) indicate that the data are significantly $(p<0.05)$ different from $0 \mathrm{dpf}, 1 \mathrm{dpf}, 2 \mathrm{dpf}$, or $3 \mathrm{dpf}$ embryos, respectively. All these mRNAs followed an equal nature of expression during Japanese rice fish embryogenesis. Figure 1.1= tet1; Figure 1.2 = tet2; Figure 1.3= tet3.
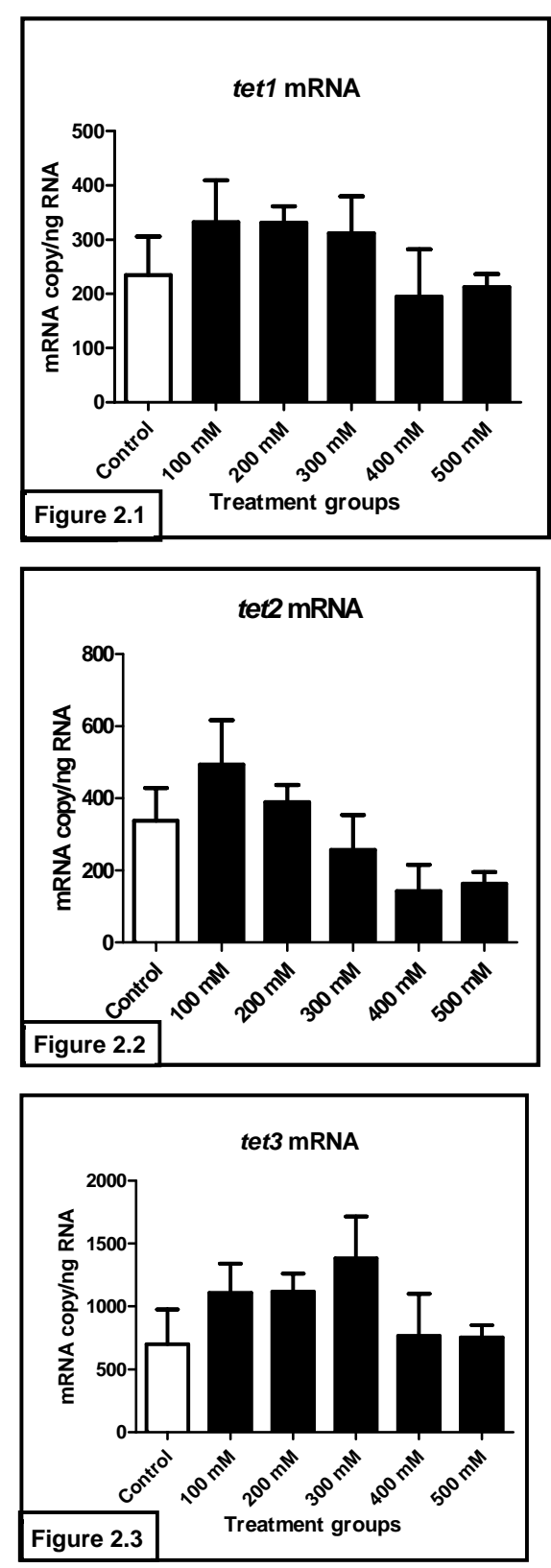

Figure 2. Effects of different ethanol concentrations (0-500 mM) on tet1, tet2, and tet $3 \mathrm{mRNA}$ of Japanese rice fish embryos on $2 \mathrm{dpf}$. Figure 2.1= tet1; Figure $2.2=$ tet2; Figure $2.3=$ tet 3 . Fertilized Japanese rice fish embryos (Iwamatsu stages 9-10) were exposed to different concentrations of ethanol (100-500 mM, 0-2 dpf), and analyzed on 2 dpf. Control embryos were maintained in ERM with no ethanol. Each bar is the mean \pm SEM of four to ten observations. The data were analyzed by one-way ANOVA followed by post-hoc Tukey's multiple comparison test. The tet 3 mRNA contents in embryos exposed to $100-500 \mathrm{mM}$ ethanol were not significantly different $(p<0.05)$ from the control (no ethanol) groups. 

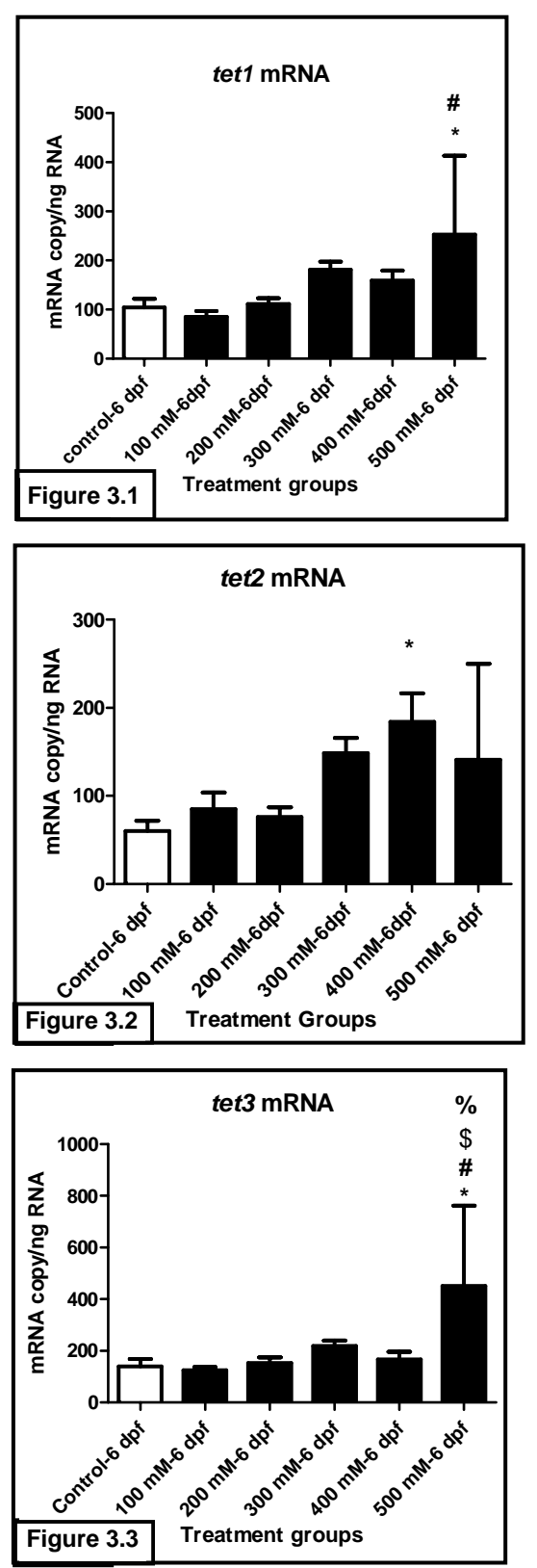

Figure 3. Effect of different ethanol concentrations on tet1, tet2, and tet 3 mRNA of Japanese rice fish embryos on 6 dpf. Figure 3.1 = tet1; Figure 3.2 = tet2; Figure 3.3 = tet3. Fertilized Japanese rice fish embryos (Iwamatsu stages 9-10) were exposed to ethanol (0-500 $\mathrm{mM}) 0-2 \mathrm{dpf}$ and then removed from the ethanol and maintained in clean ERM (no ethanol) until $6 \mathrm{dpf}$, and analyzed on $6 \mathrm{dpf}$. Each bar is the mean \pm SEM of four to ten observations. The data were analyzed by one-way ANOVA followed by post-hoc Tukey's multiple comparison test. Bar heads with asterisks $(*)$, pound $(\#)$, dollar $(\$)$, and percent $(\%)$ indicate that the data are significantly $(p<0.05)$ different from $0 \mathrm{dpf}, 1 \mathrm{dpf}, 2 \mathrm{dpf}$, or $3 \mathrm{dpf}$, embryos, respectively.
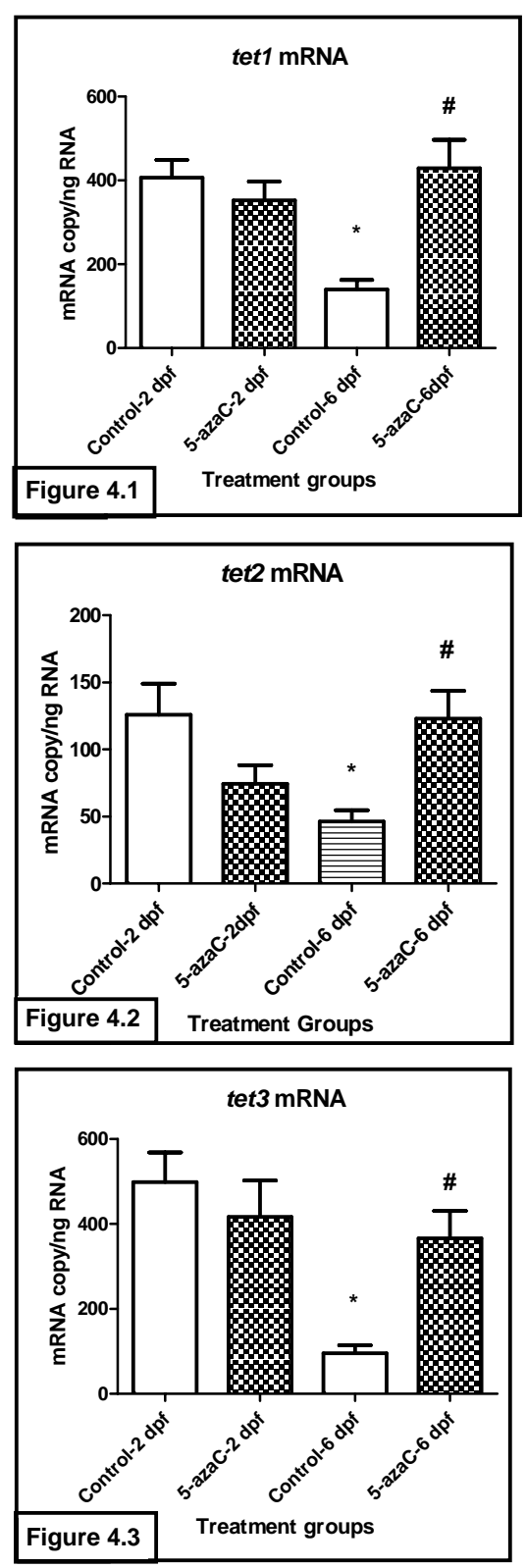

Figure 4. Effect of 5-azacytidine ( $2 \mathrm{mM})$ on tet1, tet2 and tet3 mRNA of Japanese rice fish embryos. Figure $4.1=$ tet1; Figure 4.2 = tet2; Figure $4.3=$ tet 3 . Fertilized Japanese rice fish embryos (Iwamatsu stages 9-10) were exposed to 5-azacytidine $(2 \mathrm{mM})$ and analyzed either on $2 \mathrm{dpf}$ or maintained in clean ERM 2-6 dpf without 5-azaC and analyzed on $6 \mathrm{dpf}$. Each bar is the mean \pm SEM of four to ten observations. The data were analyzed by one-way ANOVA followed by post-hoc Tukey's multiple comparison test; $p<0.05$ was considered as significant. Bar head with asterisks $(*)$ indicates that the data are significantly different from corresponding 2 dpf controls; bar head with pound (\#) symbol indicates that the data are significantly different from the corresponding $6 \mathrm{dpf}$ controls. 
Table 2. Expression of tet methylcytosine dioxygenase (tet) mRNAs in brain of male and brain, ovary, and liver of female adult reproductively active Japanese rice fish.

\begin{tabular}{|c|c|c|c|c|}
\hline $\begin{array}{c}\text { Name of } \\
\text { the gene }\end{array}$ & Brain (male) & Brain (female) & Ovary & Liver \\
\hline tet1 & $474.4 \pm 208.8$ & $398.2 \pm 40.68$ & $257.2 \pm 112.5$ & $13.36 \pm 1.44^{*}$ \\
\hline tet2 & $82.54 \pm 10.59$ & $54 \pm 8.06$ & $34.34 \pm 12.23$ & $1.06 \pm 0.41^{*}$ \\
\hline tet3 & $237.4 \pm 44.81$ & $291.1 \pm 49.98$ & $168.8 \pm 46.34$ & $1.38 \pm 0.13^{*}$ \\
\hline
\end{tabular}

The mRNA data (mean $\pm \mathrm{SEM}, \mathrm{n}=4$ ) are expressed as mRNA copy/ng RNA. Asterisks (*) indicate that the values are significantly different from the corresponding tet mRNAs of brain (male and female) and ovary of Japanese rice fish adults.

phases; the basal phase in zero dpf, the peak phase in 1-3 dpf, and the static phase from $4 \mathrm{dpf}$ until hatching. The expression of all three mRNAs was found to be significantly higher in the peak phase (1-3 dpf) than the basal phase (zero dpf) $(p<0.05)$. However, tet1 mRNA level in 1,2 and $3 \mathrm{dpf}$ remained at the same level when compared with zero dpf embryos (Figure 1.1). In the case of tet2, the mRNA level in 2 and 3 dpf were significantly higher than $1 \mathrm{dpf}$ embryos $(p<0.05)$ (Figure 1.2) and in tet3, the mRNA level in $3 \mathrm{dpf}$ was found to be significantly lower than the tet 3 mRNA found in $1 \mathrm{dpf}$ embryos $(p<0.05)$ (Figure 1.3). On day 4 onwards, tet1, 2 and 3 mRNAs were found to be significantly lower than the tet mRNAs found in the peak phase $(1-3 \mathrm{dpf} ; p<0.05)$. However, for tet1, the reduction was even lower than zero dpf $(p<0.05)$ Figure 1.1) and for tet 2 and tet 3 which were at the same level as in zero dpf (Figure 1.2 and 1.3).

\section{Effect of ethanol on the expression of tet1, tet2, and tet $3 \mathrm{mRNAs}$ during Japanese rice fish embryogenesis}

The effects of ethanol on mRNA expression of tet genes at the transcription level were investigated by RT-qPCR. Fertilized eggs (zero dpf embryos; Iwamatsu stages 9-10) were exposed to five different concentrations of ethanol $(100,200,300$, 400 , and $500 \mathrm{mM}$ ) and controls (no ethanol) for the first $48 \mathrm{~h}$ (zero-2 dpf) of development in tightly capped $2 \mathrm{~mL}$ tubes containing $1 \mathrm{~mL}$ ERM. Survived embryos (both from control and ethanoltreated group) were used for RNA extraction and mRNA analysis on $2 \mathrm{dpf}$ after the removal of the media (Figures 2.1-2.3). In another set of experiment the embryos after 2 days of ethanol treatment (zero-2 dpf) were maintained in ERM in a 48-well tissue culture plate without ethanol for another 4 days (2-6 dpf) and used for RNA extraction and analyses (Figures 3.1-3.3). Our data indicated that in the first approach, all tet mRNAs (tet1, tet2, tet3) remained unaltered on $2 \mathrm{dpf}$ embryos (immediately after ethanol removal) when compared with the corresponding controls. However, in the tet 2 mRNA, a concentration-dependent reduction (although not significantly different from each other) was observed (Figure 3.2). In the second approach (embryos were exposed to ethanol zero$2 \mathrm{dpf}$ and then maintained in ERM for another 4 days), tet 1 and tet 3 mRNAs, in comparison to controls, remained unaltered in the embryos exposed to $100-400 \mathrm{mM}$ ethanol; however, embryos exposed to $500 \mathrm{mM}$ ethanol showed significantly higher level of tet 1 mRNA when compared with those exposed to control and $100 \mathrm{mM}$ of ethanol $(p<0.05)$. But tet3 mRNA at $500 \mathrm{mM}$ concentration showed significantly higher level of mRNA in comparison with the embryos of control, 100, 200, and $400 \mathrm{mM}$ of ethanol $(p<0.05)$ groups. In the case of tet2 mRNA, the data of $400 \mathrm{mM}$ ethanol-exposed embryos showed significant difference with the control embryos only $(p<0.05)$ (Figure 3.2); others remained unaltered.

\section{Effect of 5-azaC on tet1, tet 2 and tet3 mRNA levels during Japanese rice fish embryogenesis}

Effects of DNMT inhibitor 5-azaC on the expression of mRNAs of tet genes were also investigated. The embryos were exposed to $2 \mathrm{mM} 5$-azaC zero$2 \mathrm{dpf}$ and then either used for RNA extraction or maintained in clean ERM without 5-azaC for another 4 days (2-6 dpf) followed by RNA extraction and analyses. It was observed that mRNA expression 
pattern of tet1, tet2, and tet3 were unaltered after 2 dpf of continuous $2 \mathrm{mM} 5$-azaC exposure (Figures 4.1, 4.2, and 4.3). The embryos on $6 \mathrm{dpf}$ showed significant increase in tet1, tet 2 and tet 3 mRNAs when compared with the corresponding controls $(p<0.05)$ (Figures 4.1, 4.2, and 4.3). Age-related comparison (between $2 \mathrm{dpf}$ and $6 \mathrm{dpf}$ embryos) showed that all three tet mRNAs (tet1, tet2, and tet3) were significantly reduced in control embryos on 6 dpf in comparison to control embryos of $2 \mathrm{dpf}(p<0.05)$; however, embryos exposed to $2 \mathrm{mM} 5$-azaC remained at the same level between 2 and 6 dpf of development (Figures 4.1, 4.2, and 4.3).

\section{DISCUSSION}

Our current studies on DNA demethylating enzyme genes which encode tet proteins indicated that in adult fish, the brain expressed substantially high levels of tet mRNAs compared to ovary and liver; in embryos, tet mRNAs maintained a developmental rhythm, expressed high mRNA copies during early phases of development ( 1 to $3 \mathrm{dpf}$ ) followed by down regulation (from $4 \mathrm{dpf}$ until hatching). Moreover, both ethanol (only at 400-500 mM concentrations) and 5-azaC (2 mM) were able to modulate the expression pattern of these mRNAs at the transcription level which were observed only in later stages ( $6 \mathrm{dpf})$ of development.

Our previous studies on gene expression analysis of DNA methylating enzymes showed that during development, dmnt mRNA transcripts (dnmt1, dnmt3aa, dnmt3ba, and dnmt3bb.1), like current observations on tet mRNAs, maintained a rhythmic expression pattern during Japanese rice fish embryogenesis which were modulated by both ethanol and 5-azaC [36, 37]. Dnmt enzymes catalyzed the methylation of cytosine (C) to 5methylcytosine (5mC) and approximately $70-80 \%$ of the methylated DNA were distributed on $\mathrm{CpG}$ dinucleotides ( $\mathrm{CpG}$ islands) which are mainly concentrated within the gene promoters, near transcription initiation sites. Generally, during normal development, $\mathrm{CpG}$ islands are methylated that causes the genes to be turned off $[44,45]$. However, for the progression of embryogenesis, many genes are required to be turned on; therefore, in contrast to DNA methylation, DNA demethylation at specific sites is very crucial during development.
During demethylation, the methyl group of $5 \mathrm{mC}$ within the $\mathrm{CpG}$ islands is oxidized to $5 \mathrm{hmC}$ by Tet family of enzymes (active demethylation) through a chemical reaction which involves alphaketoglutarate $(\alpha \mathrm{KG})$, Oxygen, ATP, and iron $\left(\mathrm{Fe}^{2+}\right)$. $5 \mathrm{hmC}$ is further oxidized to 5-formylcytosine $(5 \mathrm{fC})$ and 5-carboxycytosine $(5 \mathrm{CaC})$ catalyzed by Tet enzymes [46]. Therefore, $5 \mathrm{hmC}$ serves as an active demethylation mark of embryogenesis, which seems to be the signal of the initiation of base excision repair (BER) systems, by which $5 \mathrm{mC}$ will be returned to a regular unmethylated cytosine residue and able to regulate gene activation [46]. Consequently, to understand the role played by active demethylation process in FASD, we have extended our investigations on tet enzyme gene expression during Japanese rice fish development and their modulation caused by ethanol and 5-azaC, the two compounds which were able to induce FASD-like phenotypic features in this fish species [36].

Despite the role played during development, in adults, Tet proteins are functional in various organs. In brain, these proteins play a significant role in controlling neuronal differentiation, neural plasticity, and brain functions [31, 32]. Our data also indicated that adult Japanese rice fish expressed all three tet mRNA transcripts (tet1, tet2, and tet3) in brain (both male and female), and liver and ovary of female fish (Table 2). Comparison of the data among these three organs (brain, ovary, and liver) indicated that tet mRNA transcripts (tet1, 2, and 3) were found to be highest in brain which suggest that substantial amount of $5 \mathrm{hmC}$ is required in brain functions of Japanese rice fish. High levels of $5 \mathrm{hmC}$ were also detected in neurons of the brain of adult zebrafish, larval and juvenile xenopus, and mouse [47]. Although the present investigation did not include testis, presence of all three tet mRNAs in the ovarian tissue also suggested that these enzymes play a crucial role during oogenesis/gametogenesis of Japanese rice fish as observed in mice [35]. Moreover, expression of all three tet mRNA transcripts in the liver of adult fish, even though significantly lower than other two organs, suggested that $5 \mathrm{hmC}$ is necessary for the activation of metabolic genes in this organ. It was shown that $5 \mathrm{hmC}$ is a major epigenetic modification mark in the adult human liver, playing a significant role in hepatic gene expression [48, 49]. 
Our data further indicated that like DNMT, tet mRNAs also maintained a rhythmic expression pattern during development of Japanese rice fish, with high mRNA copies in early phases (1-3 dpf) between neurula (Iwamatsu stages 17-18) and 30 somite stages (Iwamatsu stages 27-28) (Figure 1). Our previous studies on dnmt mRNAs also showed high mRNA copies in early stages of development (dnmt1 from zero dpf to 2-3 dpf which corresponds to early blastula to embryos that reach $34-35$ somite stages and dnmt3a, dnmt3ba and dnmt3bb.1 from $1 \mathrm{dpf}$ to 2-3 dpf which corresponds to neurula to 34-35 somite stages). Therefore, the highest level of expression of both methylating (dnmts) and demethylating (tets) enzyme mRNAs during early phases of development is quite interesting. Although we did not study the testis, we observed that all three tet mRNAs are highly expressed in the ovary (Table 2) which suggests a possibility of maternal inheritance of these mRNAs to the eggs during fertilization. However, all three tet mRNA levels were significantly lower in zero dpf embryos (early blastula) than the embryos in $1 \mathrm{dpf}$ of development (neurula) which indicated that these tet genes are actively transcribing during and after neurula stages until the embryos reach 34-35 somite stages of development. Reports showed that although in mouse embryos Tet 3 was found to be maternally deposited, in zebrafish, the maternal deposition of tet mRNAs in the embryos are lacking [27], even though the zebrafish genome encodes tet1, tet2, and tet3 genes [50] and, also tet 2 and tet 3 are the major 5methyl cytosine dehydrogeneases during embryogenesis with overlapping functions. Moreover, significant amount of $5 \mathrm{hmC}$ in zebrafish genome was lacking until the embryos reach segmentation stage (10-11 hpf). Therefore, we predict that higher level of tet mRNAs in Japanese rice fish embryos in early stages of development (1-3 dpf) were due to transcription of tet genes rather than maternal inheritance.

Further, the comparison of mRNA expression data of dnmt (responsible for $5 \mathrm{mC}$ ) and tet (responsible for catalyzing $5 \mathrm{mC}$ to $5 \mathrm{hmC}$ ) during Japanese rice embryogenesis indicate that tet 1 , tet2, and tet3 mRNAs followed the same expression patterns as followed by all dnmt3 (dnmt3aa, dnmt3ba and dnmt3bb.1) mRNAs (reached peak level in 1-2 dpf and then down-regulate). However, expression of $d n m t 1$ is slightly different (peak level in zero- $2 \mathrm{dpf}$ and then gradual downregulation) from the expression patterns followed by dnmt3 and tet mRNAs. The highest level of expression of all three tet mRNAs together with dnmt mRNAs during early phases of development is surprising. The genomic DNA of Japanese rice fish embryos are highly methylated at CCGG sites in early stages (16 celled stage) and continue to remain methylated until hatching [38]. Moreover, higher level of dnmt mRNA transcripts at least in early developmental stages as observed by us [36] suggested a possibility of higher level of $5 \mathrm{mC}$ in the Japanese rice fish genome which seems to be necessary for the significant number of genes to be turned off during early phases of development. In contrast to dnmt mRNAs, higher level of tet mRNAs also indicate an optimum level of $5 \mathrm{hmC}$ in the genome (due to demethylation of $5 \mathrm{mC}$ ) that are necessary for demethylation and turning on some of the selective genes which are essential for normal development. Therefore, we predict that there must be an equilibrium maintained between $5 \mathrm{mC}$ and $5 \mathrm{hmC}$ levels of Japanese rice fish genome during normal development. Disruption of this ratio $(5 \mathrm{mC}: 5 \mathrm{hmC})$ may introduce developmental abnormalities as observed in FASD.

To investigate the effects of ethanol (the inducer of FASD) in tet mRNA expression pattern and comparison of the effect with a DNMT inhibitor (5-azaC), we exposed zero dpf (early blastula, Iwamatsu stages 9-10) embryos to ethanol (0-500 $\mathrm{mM})$ or 5 -azaC (2 $\mathrm{mM})$ for two consecutive days (zero-2 $\mathrm{dpf}$ ) and analyzed tet mRNAs both on $2 \mathrm{dpf}$ and $6 \mathrm{dpf}$ of development (Figures 2-4). It was observed that both ethanol (100-500 mM) and 5-azaC (2 mM were unable to produce any significant effect on tet mRNA expression on 2 dpf embryos (Figure 2 and 4) while in $6 \mathrm{dpf}$ (when the embryos were allowed to grow further in an environment which is free of ethanol or 5azaC) all tet mRNAs were found to be in an enhanced level in embryos exposed to higher ethanol concentrations (400-500 mM). Surprisingly, embryos exposed to $300 \mathrm{mM}$ ethanol (the concentration which is successfully able to induce FASD-like phenotypic features in this fish) was unable to alter the tet mRNA expression (Figure 2 and 3 ). In embryos exposed to $2 \mathrm{mM} 5$-azaC (the concentration which is able to induce FASD-like 
neurocranial deformities in this fish), on $6 \mathrm{dpf}$, all tet mRNA levels (tet1, tet2, tet3) were significantly higher than those of the control embryos (Figure 4.1, 4.2 and 4.3). We noticed that modulation of tet mRNA expression by $300 \mathrm{mM}$ ethanol concentration is almost identical with our previous studies on mRNAs of dnmt3 families (dnmt3aa, dnmt3ba, and $d n m t 3 b b .1$ ) which were unaltered in both 2 or 6 dpf embryos which were continuously exposed to $300 \mathrm{mM}$ ethanol from zero to $2 \mathrm{dpf}$; however, dnmt 1 mRNA expression in both 2 and 6 dpf was modulated by ethanol [36]. Therefore, we predict that DNA methylation catalyzed by dnmt3 families (de novo DNA methyl transferase) was likely to be demethylated by tet enzymes (tet1, tet2, tet3); however, DNA methylation catalyzed by dnmt 1 enzyme (maintenance DNA methyl transferase 1) is demethylated by the mechanisms which seems to be different from the reactions catalyzed by tet enzymes (tet1, tet2, and tet3). Another report also showed that 5 -azaC is able to retard embryonic growth as well as DNA methylation [51]. It is well established that 5 -azaC causes the reduction of DNA methylation status by inhibiting DNMT through passive demethylation pathways [52]. A recent report showed that 5 -azaC reduces the methylation status of DNA in human hepatocellular carcinoma (HCC) cell lines by triggering active demethylation pathway through the conversion of $5 \mathrm{mC}$ to $5 \mathrm{hmC}$ by inducing TET2 and TET3 proteins [53] and vitamin $C$ enhances TET activity when it combines with 5-azaC [54]. Therefore, the enhanced level of tet mRNAs by 5-azaC in 6 dpf embryos is probably due to inhibition of downregulation mechanisms rather than new synthesis.

\section{CONCLUSION}

Our studies indicated that, like dnmt mRNAs, tet mRNAs during Japanese rice fish embryogenesis maintained a rhythmic pattern of expression: high copies in early stages of development followed by downregulation in late stages. Ethanol concentration, which is able to induce FASD phenotypic features $(300 \mathrm{mM})$, is unable to induce any alteration in tet mRNA transcription both in 2 and $6 \mathrm{dpf}$; however, in embryos exposed to $2 \mathrm{mM} 5$-azaC, tet mRNAs remained unaltered in $2 \mathrm{dpf}$ and in an enhanced level in 6 dpf embryos.

\section{ACKNOWLEDGEMENTS}

We are grateful to Professor Larry Walker, National Center for Natural Product Research (NCNPR), School of Pharmacy, University of Mississippi, for his kind interest, continuous encouragement and generous support to the work. This study was partially supported by the NCNPR and Department of Biomolecular Sciences, Division of Pharmacology, School of Pharmacy, University of Mississippi, UM.

\section{CONFLICT OF INTEREST STATEMENT}

The authors have no conflict of interest associated with this publication.

\section{REFERENCES}

1. Goll, M. G. and Bestor, T. H. 2005, Annu. Rev. Biochem., 74, 481.

2. Bestor, T., Laudano, A., Mattaliano, R. and Ingram, V. 1988, J. Mol. Biol., 203, 971.

3. Hermann, A., Goyal, R. and Jeltsch, A. J. 2004, J. Biol. Chem., 279, 48350.

4. Mayer, W., Niveleau, A., Walter, J., Fundele, R. and Haaf, T. 2000, 403, 501-502.

5. Ooi, S. K. and Bestor, T. H. 2008, Cell, 133, 1145.

6. Surani, M. A. and Hojkova, P. 2010, Cold Spring Harbor Symp. Quant. Biol., 75, 211.

7. Wu, S. C. and Zhang, Y. 2010, Nat. Rev. Mol. Cell Biol., 11, 607.

8. Bogdanovic, O., Smits, A. H., de la Calle Mustienes, E., Tena, J. J., Ford, E., Williams, R., Senanayake, U., Schultz, M. D., Hontelez, S., van Kruijsbergen, I., Rayon, T., Gnerlich, F., Carell, T., Veenstra, G. J. C., Manzanarea, M., Sauka-Spengler, T., Ecker, J. R., Vermeulen, M., Gomez-Skarmeta, J. L. and Lister, R. 2016, Nat. Gen., 48, 417.

9. Seisenberger, S., Peat, J. R., Hore, T. A., Santos, F., Dean, W. and Reik, W. 2013, Phil. Trans. R. Soc. B, 368, 20110330.

10. Tahiliani, M., Koh, K. P., Shen, Y., Pastor, W. A., Bandukwala, H., Brudno, Y., Agarwal, S., Iyer, L. M., Liu, D. R., Aravind, L. and Rao, A. 2009, Science, 324, 930.

11. He, Y. F., Li, B. Z., Li, Z., Liu, P., Wang, Y., Tang, Q., Ding, J., Jia, Y., Chen, Z., Li, L., Sun, Y., Li, X., Dai, Q., Song, C., Zhang, K., He, C. and $\mathrm{Xu}, \mathrm{G}-\mathrm{L}$. 2011, Science, 333, 1303. 
12. Potok, M. E., Nix, D. A., Parnell, T. J. and Cairns, B. R. 2013, Cell, 153, 759-772.

13. Jiang, L. 2013, Cell, 153, 773-784.

14. Ono, R., Taki, T., Taketani, T., Taniwaki, M., Kobayashi, H. and Hayashi, Y. 2002. Cancer Res., 62, 4075.

15. Lorsbach, R. B., Moore, J., Mathew, S., Raimondi, S. C., Mukatira, S. T. and Downing, J. R. 2003, Leukemia, 17, 637.

16. Ito, S., D'Alessio, A. C., Taranove, O. V., Hong, K., Sowers, L. C. and Zhang, Y. 2010, Nature, 466, 1129.

17. Wu, H. and Zhang, Y. 2011, Genes Dev., $25,2436$.

18. Gu, T. P., Gou, F., Yang, H., Wu, H. P., Xu, G. F., Liu, W., Xie, Z. G., Shi, L., He, X., Jin, S. G., Iqbal, K., Shi, Y. G., Deng, Z., Szabo, P. E., Pfeifer, G. P., Li, J. and Xu, G. L. 2011, Nature, 477, 606.

19. Iqbal, K., Jin, S. G., Pfeifer, G. P. and Szabo, P. E. 2011, Proc. Natl. Acad. Sci., 108, 3642.

20. Wossidlo, M., Nakamura, T., Lepikhov, K., Marques, C. J., Zakhartchenko, V., Boiani, M., Arand, J., Nakano, T., Reik, W. and Walter, J. 2011, Nat. Commun., 2, 241.

21. Dawlaty, M. M., Ganz, K., Powell, B. E., Hu, Y. C., Markoulaki, S., Cheng, A. W., Gao, Q., Kim, J., Choi, S. W., Page, D. C. and Jaenisch, R. 2011, Cell Stem Cell, 9, 166.

22. Li, Z., Cai, X., Cai, C. L., Wang, J., Zhang, W., Petersen, W, Petersen, B. E., Yang, F. C. and Xu, M. 2011, Blood, 118, 4509.

23. Moran-Crusio, K., Reavie, L., Shih, A., Abdel-Wahab, O., Ndiaye-Lobry, D., Lobry, C., Figueroa, M. E., Vasanthakumar, A., Patel, J., Zhao, X., Perna, F., Pandey, S., Madzo, J., Song, C., Dai, Q., He, C., Ibrahim, S., Beran, M., Zavadil, J., Nimer, S. D., Melnick, A., Godley, L. A., Aifantis, I. and Levine, R. L. 2011, Cancer Cell, 20, 11.

24. Shide, K., Kameda, T., Shimoda, H., Yamaji, T., Abe, H., Kamiunten, A., Sekine, M., Hidaka, T., Katayose, K. and Kubuki, Y. 2012, Leukemia, 26, 2216.

25. Kohli, R. M. and Zhang, Y. 2013, Nature, $502,472$.

26. Ko, M., Bandukwala, H. S., An, J., Lamperti, E. D., Thompson, E. C., Hastie, R., Tsangaratou, A., Rajewsky, K., Koralov, S. B. and Rao, A. 2011, Proc. Natl. Acad. Sci. USA, 108, 14566.
27. Li, C., Lan, Y., Schwartz-Orbach, L., Korol, E., Tahiliani, M., Evans, T. and Goll, M. G. 2015, Cell Reports, 12, 1133-1143.

28. Szulwach, K. E., Li, X., Li, Y., Song, C. X., Wu, H., Dai, Q., Irier, H., Upadhyay, A .K., Gearing, M., Levey, A. I., Vasanthakumar, A., Godley, L. A., Chang, Q., Cheng, X., He, C. and Jin, P. 2011, Nat. Neurosci., 14, 1607.

29. Dzitoyeva, S., Chen, H. and Manev, H. 2012, Restor. Naurol. Neurosci., 30, 237.

30. Khare, T., Pai, S., Koncevicius, K., Pal, M., Kriukiene, E., Liutkeviciute, Z., Irimia, M., Jia, P., Ptak, C., Xia, M.,Tice, R., Tochigi, M., Morera, S., Nazarians, A., Belsham, D., Wong, A. H., Blencowe, B. J., Wang, S. C., Kapranov, P., Kustra, R., Labrie, V., Klimasauskas, S. and Petronis, A. 2012, Nat. Struct. Mol. Biol., 19, 1037.

31. Santiago, M., Antunes, C., Guedes, M., Sousa, N. and Marques, C. J. 2014, Genomics, 104, 334.

32. Mi, Y., Gao, X., Dai, J., Ma, Y., Xu, L. and Jin, W. 2015, Int. J. Mol. Sci., 16, 21846-21857.

33. Pirola, C. J., Scian, R., Gianotti, T. F., Dopazo, H., Rohr, C., Martino, J. S., Castano, G. O. and Sookoian, S. 2015, Madicine (Baltimore), 94, e1480.

34. Ni, K., Dansraniavin, T., Rogenhofer, N., Oeztuerk, N., Deuker, J., Bergmann, M., Schuppe, H. C., Wagenlehner, F., Weidner, W., Steger, K. and Schagdarsurengin, U. 2016, Hum Reprod., 31, 1411.

35. Qian, Y., Tu, J., Tang, N. L., Kong, G. W., Chung, J. P., Chan, W. Y. and Lee, T. L. 2015, Int. J. Biochem. Cell Biol., 67, 121-127.

36. Dasmahapatra, A. K. and Khan, I. A. 2015a, Comp. Biochem. Physiol. Part C Toxicol. Pharmacol., 176-177, 1.

37. Dasmahapatra, A. K. and Khan, I. A. 2016, Comp. Biochem. Physiol. Part C, Toxicol. Pharmacol., 179, 174-183.

38. Walter, R. B., Li, H. Y., Intano, G. W., Kazianis, S. and Walter, C. A. 2002, Comp. Biochem. Physiol. B Biochem. Mol. Biol., 133, 597.

39. Dasmahapatra, A. K. and Khan, I. A. 2015b, Comp. Biochem. Physiol. Part C Toxicol. Pharmacol., 167, 90.

40. Haron, M. H., Powe, D., Khan, I. A. and Dasmahapatra, A. K. 2012, Adv. Mol. Toxicol., 6,77 . 
41. Iwamatsu, T. 2004, Mech. Dev., 121, 605.

42. Hu, Y., Willett, K. W., Khan, I. A., Scheffler, B. E. and Dasmahapatra, A. K. 2009, Comp. Biochem. Physiol. C Toxicol. Pharmacol., 150, 495.

43. Wu, M., Hu, Y., Ali, Z., Khan, I. A., Verlangeiri, A. and Dasmahapatra, A. K. 2010, Chem. Res. Toxicol., 23, 1405.

44. Ndlovu, M. N., Denis, H. and Fuks, F. 2011, Trends Biochem. Sci., 36, 381.

45. Auclair, G. and Weber, M. 2012, Biochimie, 94, 2002.

46. Liyanage, V. R. B., Jarmasz, J. S., Murugeshan, N., Del Bigio, M. R., Rastegar, M. and Davie, J. R. 2014, Biology, 3, 670.

47. Diotel, N., Merot, Y., Coumailleau, P., Gueguen, M. M., Serandour, A. A., Salbert, G. and Kah, O. 2016, J. Comp. Neurol., Doi:10.1002/cne.24077.

48. Ivanov, M., Kals, M., Kacevska, M., Barragan, I., Kasuga, K., Rane, A., Metspalu, A., Milani, L. and Ingelman-Sundberg, M. 2013, Genome Biol., 14, R83.

49. Seelinger, C., Culmes, M., Schyschka, I., Yan, X., Damm, G., Wang, Z., Kleeff, J., Thasler, W. E., Hengstler, J., Stockle, U., Ehnert, S. and Nussler, A. K. 2013, Cell Transplant, 22, 119.

50. Almeida, R. D., Loose, M., Sottile, V., Matsa, E., Denning, C., Young, L., Johnson, A. D., Gering, M. and Ruzov, A. 2012, Epigenetics, 7, 383.

51. Zhou, F. C., Chen, Y. and Love, A. 2011, Birth Defects Res. A Clin. Exp. Res., 91, 703-715.

52. Christman, J. K. 2002, Oncogene, 21, 5483.

53. Sajadian, S. O., Ehnert, S., Vakilian, H., Koutsouraki, E., Damm, G., Seehofer, D., Thasler, W., Dooley, S., Baharvand, H., Sipos, B. and Nussler, A. K. 2015, Clin. Epigenetics, 7, 98 .

54. Sajadian, S. O., Tripura, C., Samani, F. S., F. S., Ruoss, M., Dooley, S., Baharvand, H. and Nussler, A. K. 2016, Clin. Epigenetics, 30, 8. 